\title{
NEOLIBERALISMO, POSTMODERNIDAD Y DESVENTURAS DEL URBANISMO EN LA GIUDAD DE MÉXICO
}

\section{NEOLIBERALISM, POST-MODERNITY AND MISFORTUNES OF URBAN PLANNING IN MEXICO GITY}

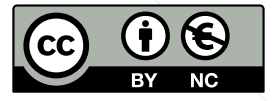

\author{
Gerardo G. Sánchez Ruiz \\ Universidad Autónoma Metropolitana-Azcapotzalco \\ México
}

Ingeniero Arquitecto por la Escuela Superior de Ingeniería y Arquitectura del IPN. Maestro en Planificación por la Sección de Graduados de la ESIA del IPN, y. Doctor en Urbanismo por la Facultad de Arquitectura de la UNAM. Profesor e Investigador de Tiempo Completo en la División de Ciencias y Artes para el Diseño de la Universidad Autónoma Metropolitana-Azcapotzalco; y profesor de asignatura en la carrera de Urbanismo de Facultad de Arquitectura de la UNAM. Miembro del Sistema Nacional de Investigadores (SNI) Nivel 2. Ha participado en siete libros como autor el último Precursores del urbanismo en México. México, Trillas/UAM-A, 1913; y en veintitrés libros colectivos, el último: "La colonia Roma entre las oscilaciones del urbanismo y el posturbanismo" en Huaman Herrrera Elías A. y Cisneros Sosa Armando. Crítica de la producción del espacio urbano. México: Universidad Autónoma Metropolitana-A. 2016. Ha ofrecido cursos y conferencias en el país y en el extranjero. Tiene siete reconocimientos, el último: Mérito al Mejor Investigador Social-Urbano 2014. Otorgado por el Centro de Ciencias del Diseño y de la Construcción de la Universidad Autónoma de Aguascalientes en 2015.

gsr@azc.uam.mx

orcid.org/0000-0001-7719-3558

Fecha de recepción: 07 de diciembre, 2019. Aceptación: 08 de abril, 2020. 


\section{Resumen}

El discurrir de la Ciudad de México en el siglo XXI se caracteriza por una elevada concentración poblacional de carácter metropolitano, que ha incorporado periferias de zonas privilegiadas en Huixquilucan, Atizapán 0 Santa Fe, y otras, extendidas en municipios pobres como Ecatepec, Chimalhuacán o Tecámac lugares donde son patentes: la irregularidad, la falta de servicios, recorridos largos y pesados, inseguridad. Si bien el conjunto de la ciudad ha continuado una dinámica dibujada desde principios del siglo XX, por los efectos derivados de una postmodernidad sustentada en el neoliberalismo y en condiciones globales, sus contradicciones se han incrementado generando contradictorios procesos urbano arquitectónicas. De ahí el objetivo de este trabajo, de resaltar características de esos procesos, junto a intentos de los distintos gobiernos por aplicar acciones urbanismo pretendiendo dirigir esas formas de expansión.

\section{Palabras clave}

Neoliberalismo, postmodernidad, procesos económicos, metropolización, contradicciones sociales.

\section{Abstract}

The current course of Mexico City in the 21st century is characterized by a high population concentration of metropolitan nature which has incorporated peripheries of privileged areas in Huixquilucan, Atizapán or Santa Fe; and others, extended over poor municipalities such as Ecatepec, Chimalhuacán or Tecámac, places where irregularity, lack of services, long and heavy routes, and insecurity are evident. Although the city as a whole has shown a steady development since the early twentieth century, as a result of its postmodern movement based on neoliberal and worldwide conditions, its contradictions have increased generating contrasting architectural urban processes. Thus, the objective of this work is to highlight the features of these processes, along with the attempts of the different governments to implement urban planning actions, which help redirect these forms of urban expansion.

\section{Keywords}

Neoliberalism, postmodernity, economic processes, metropolization, social contradictions. 


\section{Introducción}

El discurrir de la Ciudad de México en el siglo XXI ocurre entre condicionantes internas y externas, entre las primeras: la irrupción de un neoliberalismo que ha disminuido la intervención del Estado en cuestiones públicas y ha incrementado inversiones privadas ligadas a transnacionales; una elevada concentración poblacional de carácter metropolitano que ha incorporado periferias otrora lejanas como los ahora populosos municipios de Ecatepec, Valle de Chalco, Tecámac, Villa Nicolás Romero, donde son patentes problemas de acceso a servicios básicos, recorridos cada vez más largos y pesados, e inseguridad, y; el surgimiento de asentamientos de zonas privilegiadas como Santa Fe o partes centrales de la ciudad donde las condiciones son distintas. Lo anterior, en un entorno de inserción del país en los grandes bloques económicos del mundo, y en ambientes sociales donde se despliegan nuevas tecnologías de comunicación, con instrumentos como la internet, carteles de todo tipo, y medios televisivos; espacios desde donde se genera una transculturación que homogeneiza actitudes y lugares.

Como determinantes de ese transitar de la ciudad deben considerarse: los caracteres de una nueva modernidad a la que sencillamente se le ha denominado postmoderna; un ambiente de sobreproducción de bienes y servicios donde ha sido fundamental la globalización, y un neoliberalismo que se ha hecho rapaz por la manera en que se ha desplegado. En ese proceso, como resultado de nuevas aspiraciones con influencia de medios de comunicación masiva, los satisfactores deseados se han convertido en carencias que van desde: las que pueden manifestarse como superfluas, como el anhelo de habitar un conjunto residencial con rebuscadas formas arquitectónicas, hasta las tangibles como requerir un simple techo para guarecerse. Carencias que pueden situarse en los planos ideológicos regidos por la competencia y la consecución de mejores posiciones sociales, y de las reales provenientes de las condiciones materiales de la población, en particular, de aquella que busca cubrir mínimos para sobrevivir.

En este contexto, se observan acciones de un urbanismo que busca atender la expresión territorial de esos efectos, pero en condiciones limitadas y por tanto con resultados poco eficaces, debido a que, a pesar de seguir pesando la decisión estatal, en buen grado se atienden preferentemente necesidades de grupos privados. De ahí la pretensión del trabajo de resaltar algunas características de la condición postmoderna objetivada en la Ciudad de México, traducida en modificaciones de los espacios existentes con el fin de alojar las actividades de la nueva modernidad, a través de acciones de un urbanismo que a todas luces se conduce en situaciones contradictorias.

Neoliberalismo, Postmodernidad, globalidad y los territorios

La necesidad del capital de reciclarse lo cual le ha permitido no extinguirse como se profetizaba por los críticos del sistema, ha obligado con la ayuda de la tecnología, a revolucionar las formas de producir, no obstante, hubo de recurrir a otras formas de conducirse. En efecto, desde fines de los años cuarenta del siglo pasado, ante la percepción de que las ganancias no fluían libremente "la Sociedad de Mont-Pèlerin, cónclave intelectual y plataforma ideológica [...] dio cause a la difusión del pensamiento y las doctrinas neoliberales" (PueIlo-Socarrás, 2015, p. 21). Así, desde los años setenta particularmente en Estados Unidos y el Reyno Unido, fluyeron acciones para modificar la manera en que se había venido regulando la economía para así activarla. Lo anterior exigió la transformación de las funciones del Estado de bienestar o interventor, al clamar empresarios la reducción de las restricciones impuestas por este en las actividades económicas, y así concretar una mayor libertad para la consecución de ganancias, con lo que se condujo a la mayor parte 
del mundo hacia un nuevo liberalismo o neoliberalismo, del cual Puello-Socarrás, apunta:

El neoliberalismo es, simplemente, el capitalismo hoy por hoy realmente existente. Desde una visión cronológica, se trata de la fase ulterior en este modo de producción social. Sin embargo, se trata también del período en el cual se verifica la exacerbación cuantitativa y cualitativa de las lógicas y contradicciones inherentes a la acumulación incesante del capital. La expansión de los mercados ("globalización") a nivel mundial, por un lado y, por el otro, los niveles de explotación económica, dominación política, opresión social y alienación ideológica que ello supone, ilustran las dimensiones: espacial, temporal y social del neoliberalismo como fase superior del capitalismo (Puello-Socarrás, 2015, p. 22).

Con esa urgencia de dar un nuevo carácter a las economías, se asistió al despliegue de otra época social y cultural. Wright Mills ante las evidentes modificaciones mundiales y, en la necesidad de afinar perspectivas y maneras de observar los nuevos fenómenos, desde 1959 alertó de la aparición de esta nueva época al señalar: "Así como la Edad Antigua fue seguida de varios siglos de predominio oriental, que los occidentales Ilamaron, [...] la Edad Media o Edad del Oscurantismo, así ahora la Edad Moderna empieza a ser seguida por una edad posmoderna" (Mills, 1969 , p. 178). Esa postmodernidad, ${ }^{1}$ en un proceso de rupturas y continuidades, motivó nuevas perspectivas en el mundo de las ideas, relaciones sociales, uso de las tecnologías, manifestaciones culturales (Fredric Jameson, 1991) y por supuestos modifica- ciones territoriales. Indefectiblemente, la renovación económica, social, tecnológica, cultural y territorial, generó inquietudes entre estudiosos, quienes se impusieron la tarea de explicar los nuevos fenómenos, para intentar adecuarse a ellos (Alain Touraine, 2000). De manera que en La condición postmoderna (1998), Jean-François Lyotard señala:

El < redespliegue $>>$ económico en la fase actual del capitalismo, ayudado por la mutación de técnicas y tecnologías, marcha a la par [...], con un cambio de función de los Estados: a partir de ese síndrome se forma una imagen de la sociedad que obliga a revisar seriamente los intentos presentados como alternativa. Digamos, para ser breves, que las funciones de regulación y, por tanto, de reproducción, se les quitan y se les quitarán más y más a los administradores y serán confiadas a autómatas. La cuestión principal se convierte y se convertirá más aún en poder disponer de las informaciones que estos últimos deberán tener memorizadas con objeto de que se tomen las decisiones adecuadas [...]. La clase dirigente es y será cada vez más la de «quienes deciden» (Lyotard, 1998, pp. 35-36).

Ahora bien, esos cambios, dadas las tecnologías de la información se sucedieron en condiciones globales, entonces las economías al liberarse crearon nuevas relaciones entre empresas y países, pero además se dio un nuevo sentido a ideas y cultura. En ese contexto, Jameson (2000) destaca el uso de instrumentos mediáticos como difusores de las ideas dominantes, ante la manera en que estos fueron tejiendo una cultura global que ha tendido

\footnotetext{
${ }^{1}$ Octavio Paz al respecto dice: "La crítica, con cierto retraso, ha advertido que desde hace más de un cuarto de siglo hemos entrado en otro período histórico y en otro arte. Se habla mucho de la crisis de la vanguardia y se ha popularizado, para llamar a nuestra época, la expresión «la era postmoderna». Denominación equívoca y contradictoria, como la idea misma de modernidad. Aquello que está después de lo moderno no puede ser sino lo ultramoderno: una modernidad todavía más moderna que la de ayer [...] Llamarse postmoderno es una manera más bien ingenua de decir que somos muy modernos" (Paz, 1993, p. 515).
} 
a la homogenización, por lo que señala: "De lo que nos damos cuenta entonces, es de que ninguna sociedad ha estado nunca tan estandarizada como esta, y de que la corriente de temporalidad humana, social e histórica no ha fluido nunca de un modo tan homogéneo" (Jameson, 2000, p. 29); y argumenta:

Nuestra época es la de la televisión o variedades mediáticas postnaturales y postastronómicas [...] de tal modo que sus grandes rotaciones -en deportes, coches último modelo, moda, televisión, año escolar o la reentré- simulan por interés comercial ritmos que antes eran naturales, y reinventan imperceptiblemente categorías arcaicas (p. 29).

En esa dinámica, si bien en esa homogeneización sobresalen particularidades de las culturas dominantes, en cada región se fundieron con lo existente. Ya desde 1933 el arquitecto Manuel Amábilis al resaltar la manera en que se conducía la sociedad y la cultura, donde era patente un proceso de "universalización del arte; la imprenta y el comercio", afirmaba que "la mezcla de las razas y la imitación de costumbres extranjeras, así como los últimos y prodigiosos adelantos de la ciencia", habían producido en la "civilización de los pueblos un hibridismo profundo". En esa vía, caracterizando al urbanismo y a la arquitectura para el caso de México decía:

Este hibridismo cada vez más intenso, nos conducirá poco a poco a la destrucción de las fronteras, a la unificación de las razas, a la paz sobre la tierra. Por esto nuestro arte debe respetar profundamente este hibridismo naciente, este cosmopolitismo, no para diluirse en él, perdiendo toda su personalidad, sino al contrario, para que, abarcándolo, comprendiéndolo, sintonice a su policorde diapasón el diapasón de los ritmos de nuestro arte propio, ampliando así éste y enriqueciendo, con el arte nacional, el arte universal. No se trata pues de nulificarse en un universalismo impersonal, sino de saber expresar con nuestro arte, este hibridismo, este cosmopolitismo característico de la civilización actual (Amábilis, 1933, pp. 34-35).
Ineludiblemente, la dinámica, neoliberal, global y postmoderna, ha moldeado a las sociedades a la vez que, a sus asientos territoriales, de tal manera que en el mundo se observan nuevos fenómenos sociales y, como apuntaría Koolhaas (1997), de creación de espacios genéricos. Entonces, la reducción del Estado interventor y de su participación en las economías, dio paso a un neoliberalismo con cambios en las maneras de producir y hacer circular las mercancías, a la aparición de nuevos eslabonamientos y a la conformación o reagrupación de los mercados (Mittelman, 2000), impulsando por supuesto, la reestructuración de espacios junto a sus expresiones arquitectónicas (Aldo Rossi, 1966).

La modernidad mutó a postmodernidad, con lo que se transformaron formas de producir y comercializar, maneras de resolver cuestiones financieras, modas del vestir o expresarse, matices en la edificación de espacios para habitar, modos de solventar traslados al interior y con el exterior de las ciudades y, hasta la más simple y fugaz forma de comer, se modificó y se homogeneizó. Lo último si se considera que, la necesidad de alimentarse ante la dinámica en que han caído aquellas, es resuelta en espacios de comida rápida pertenecientes a franquicias, sea en Barcelona, New York, Londres, Buenos Aires, Moscú o México, donde el sabor de aquella es parecido, pero satisfacen los deseos y apremios de los consumidores.

Los capitales requerían nuevas condiciones y las construyen, por lo que en el presente opera una profunda transformación de espacios urbano arquitectónicos, para alojar a cada una de sus actividades, de los cuales destacan los espacios corporativos y de comercios personificados en lugares como el Barrio de la Defensa en París, Potsdamer Platz en Berlín, Moscú City en Moscú o La zona de Las Condes en Santiago de Chile (Ver Figuras 1, 2, 3, 4), junto a muchos otros extendidos por todo el mundo. Todos ellos alojando nuevos procesos económicos, tecnológicos y culturales; de tal manera que los discursos y actuar del urbanismo y la arquitectura también se han ido transformando, para cubrir esas exigencias. 
Figura 1. El influyente corporativo: La Defensa en París

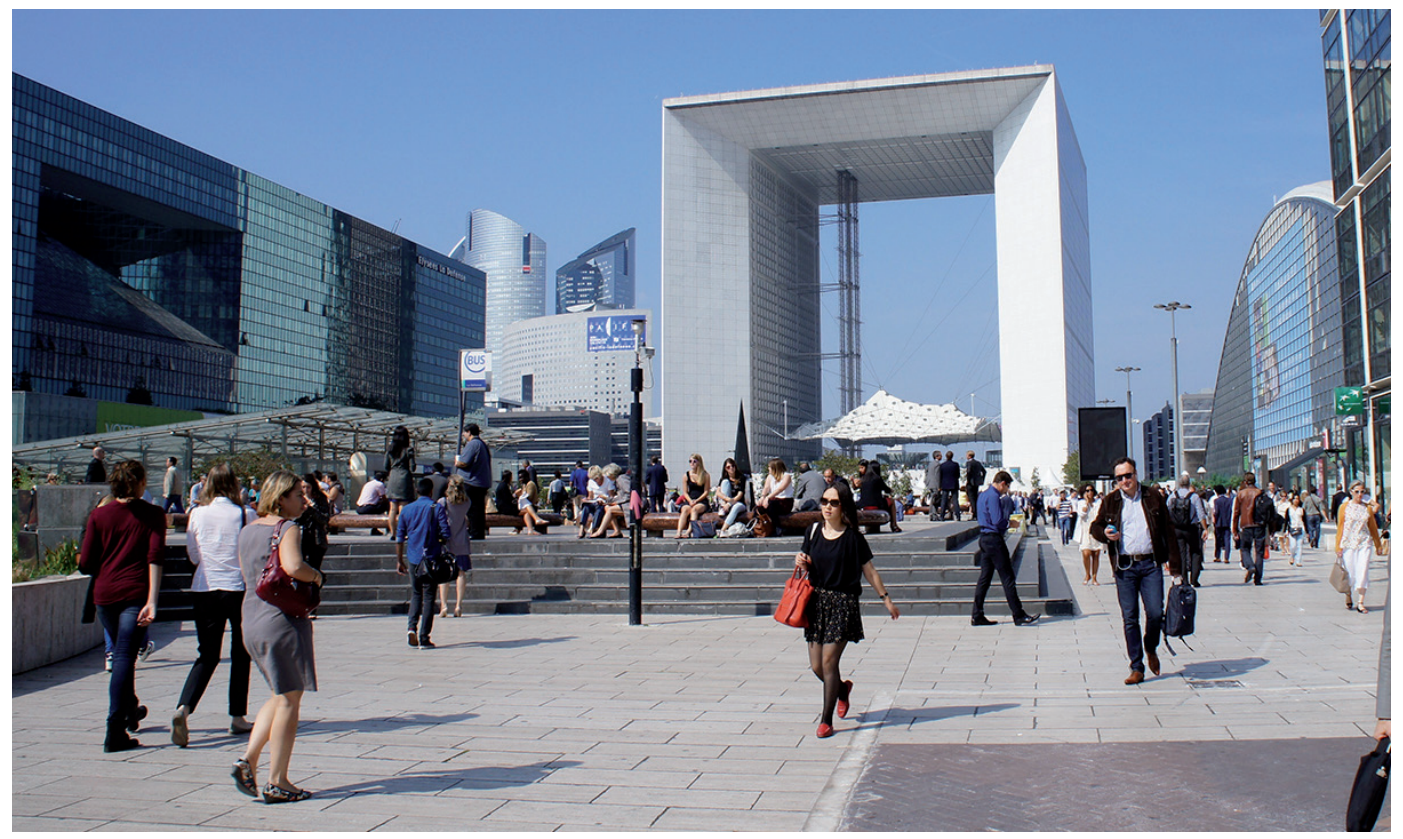

Fuente: Sánchez, (2014).

Figura 2. Potsdamer Platz en Berlín, redirigiendo la postmodernidad

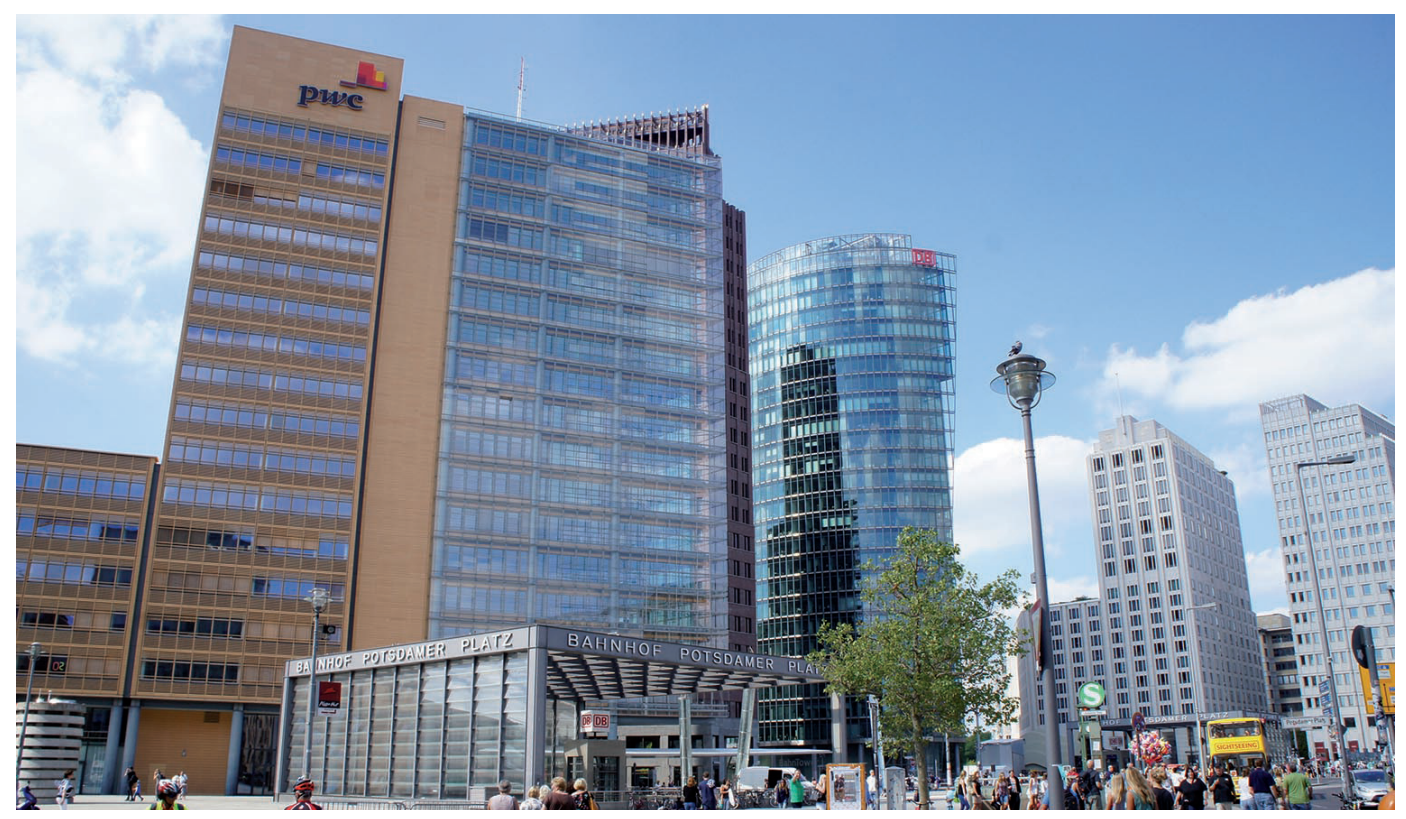

Fuente: Sánchez, (2015).

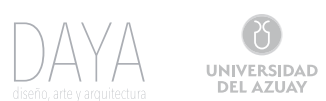


La aspiración es hacia espacios con otras imágenes, atrayentes, sustentables, tecnologizados, bien comunicados y con buenos niveles de seguridad, de los cuales se encargan pequeñas y grandes desarrolladoras inmobiliarias muchas de ellas ligadas a grandes holdings. De ese modo, hay una dinámica de producción de espacios los que, por sus atributos en planta, alzado y tiempo, pueden ser disfrutados por los distintos sectores sociales, y como extensión, usufructuados por los grupos empresariales que los impulsan. Es de ese modo que las búsquedas de otras cualidades en los espacios, han exigido nuevas funciones e imágenes a la arquitectura y al urbanismo, y en esos objetivos se han centrado sus proyectistas.

Figura 3. Moscú con parte de su postmodernidad: Moscú City

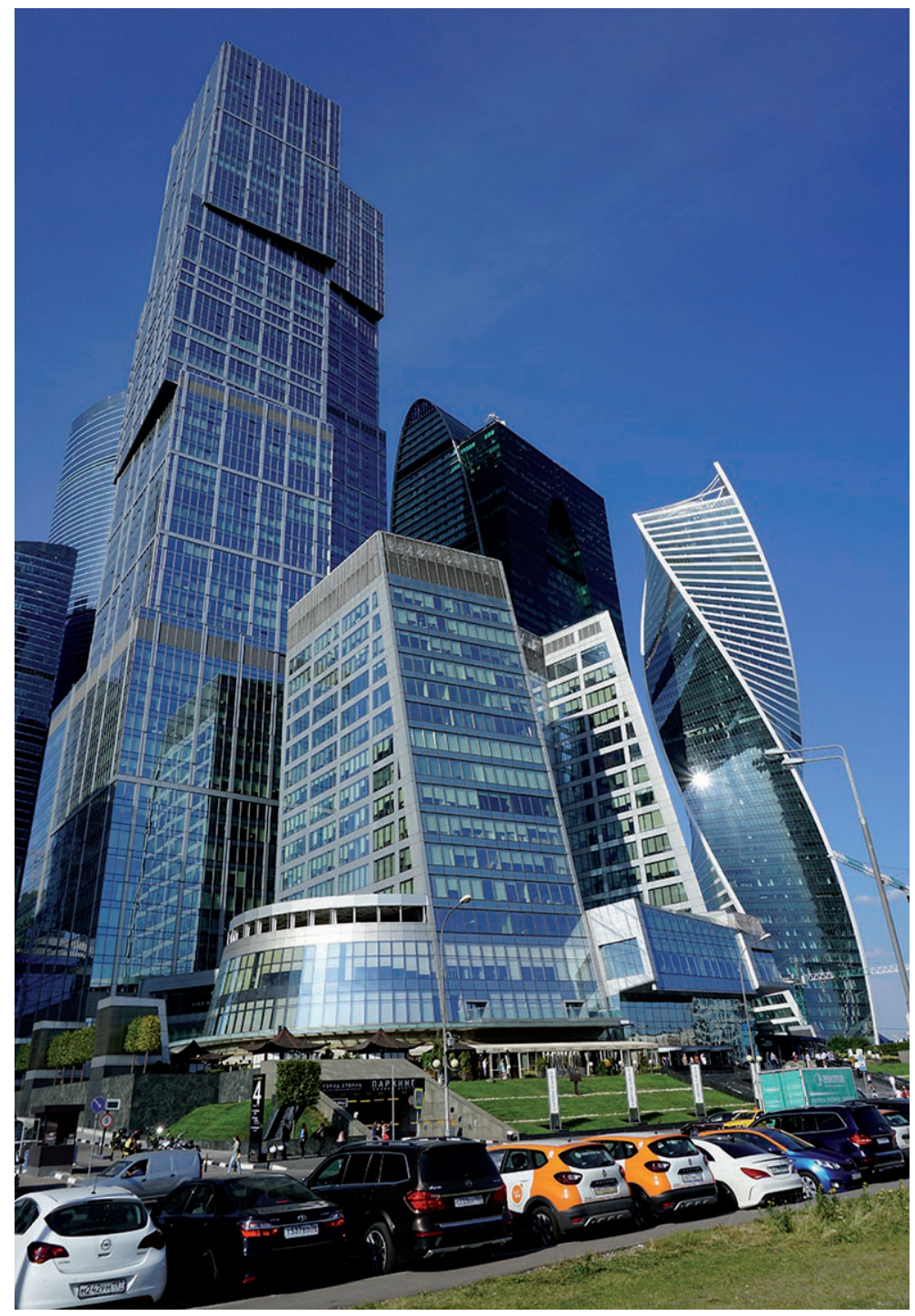

Fuente: Sánchez, (2018).

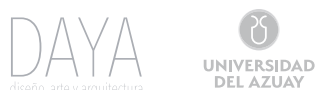


No obstante, en ese desenvolvimiento de la postmodernidad, donde las ideologías han uniformizado al nuevo ser y estar en las ciudades, subsisten intentos de grupos locales que buscan mantener formas culturales de su tradición y en algunos casos como lo es el de los migrantes, promoviendo 0 contribuyendo a la transculturación 0 al transnacionalismo al rescatar raíces de lo convenido como nacional o regional (Smith, 2001), para plasmarlo en los territorios que ocupan fuera de sus lugares de origen, tal como ocurre con áreas de migrantes establecidas en ciudades norteamericanas, donde se producen expresiones urbano arquitectónicas de diversa índole, tal como ocurre con los Chinatown en diversas ciudades, 0 en escala menor por ejemplo, con proyectos impulsados por pequeños grupos de migrantes mexicanos en Chicago. ${ }^{2}$

Figura 4. La zona de Las Condes en Santiago de Chile

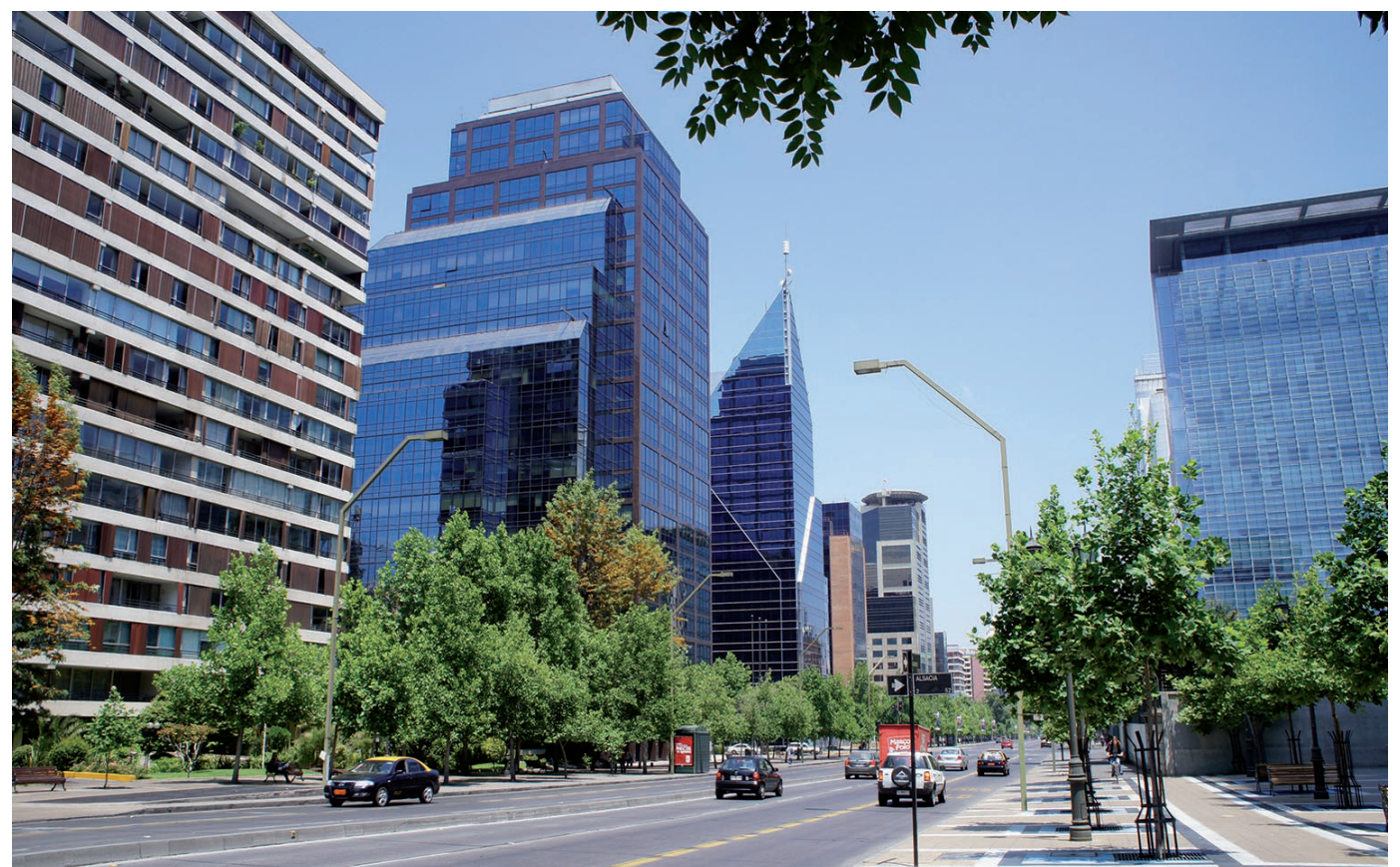

Fuente: Sánchez, (2014).

${ }^{2}$ Esos procesos Smith los enumera así: "1. El reposicionamiento discursivo de las ciudades respecto a los estados-nación en el debate actual sobre el significado de la globalización. 2. El surgimiento de redes políticas e institucionales entre naciones [...]. 3. La facilitación de lazos sociales internacionales [...]. 4. (Se sigue de éstos) la reconfiguración espacial de las redes sociales que facilitan la reproducción de la migración, de las prácticas de negocios, de creencias culturales y de organismos políticos (Smith, 2001:166). 
De ahí que a la vez puedan encontrarse edificios con rasgos de lo "mexicano" en proyectos como el de la Escuela Elemental Cesar Chávez (1993) del despacho Ross Barney \& Jankowsky Inc. localizada en la avenida South Marshfield en uno de los barrios mexicanos de Chicago; 0 edificios como el Heritage Plaza (1987) en Houston de la firma M.
Nasr \& Partners, o la Biblioteca Pública de San Antonio Texas (1995) obra del arquitecto Ricardo Legorreta (Ver Figura 5), entonces, los caracteres del mundo moderno han sufrido transformaciones, las culturas se interrelacionan se funden para dar cuerpo a otras, a la vez que a sus sustentos urbano arquitectónicos.

Figura 5. Biblioteca pública en San Antonio Texas

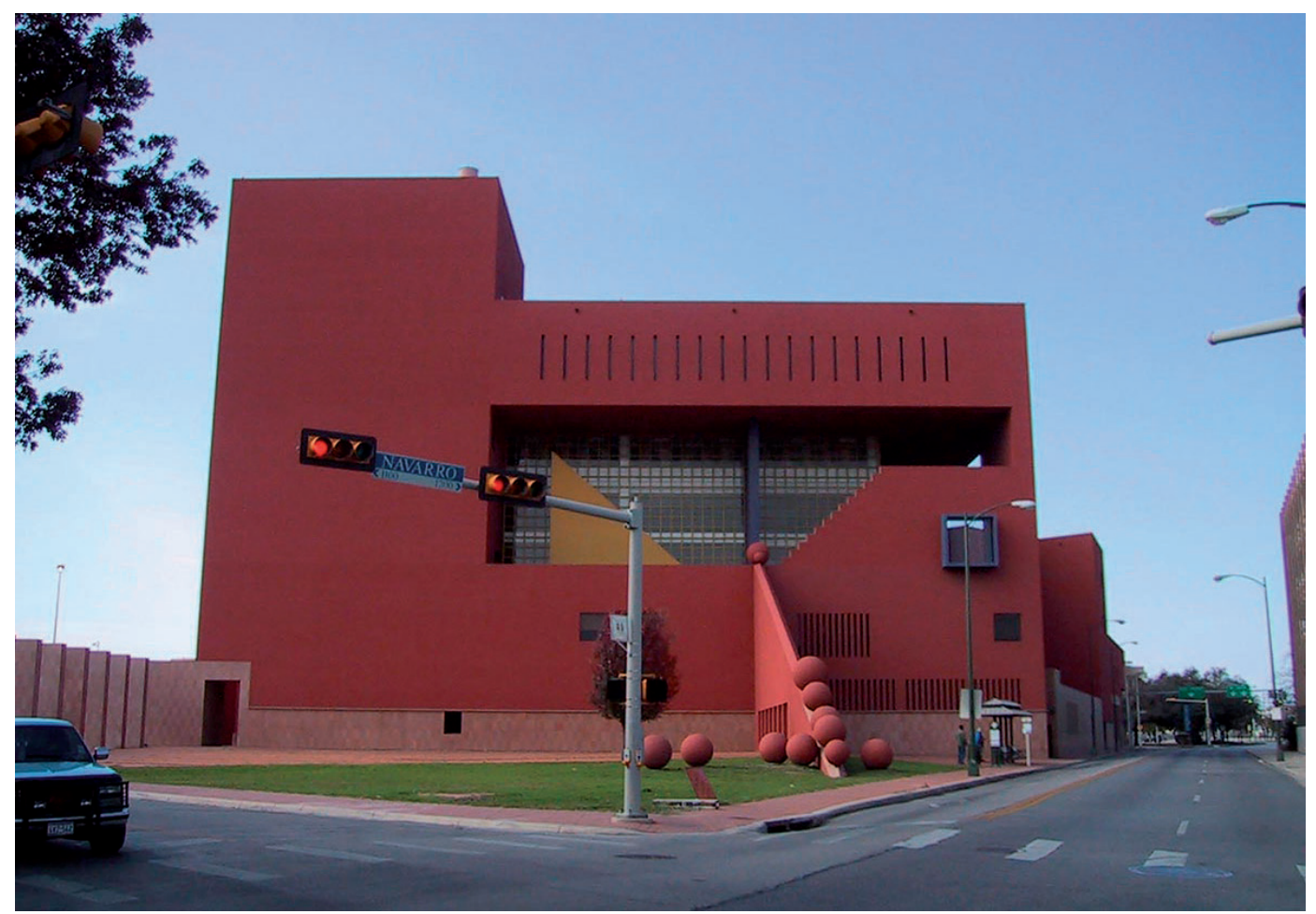

Fuente: Sánchez, (1995).

Así, la búsqueda por interpretar o conceptualizar los fenómenos ocurridos en las ciudades, ha generado interpretaciones de particularidades y de los conjuntos, como se evidencia en la multiplicidad de estudios, tales como, Posmodern urbanism (1996) de Nan Ellin; Local y global. La gestión de las ciudades en la era de la información (1997) de Jordi Borja y Manuel Castells; Postmetrópolis (2000) de Edward W. Soja; The posmodern urban condition
(2000) de Michael J. Dear; Splintering urbanism (2001) de Stephen Graham y Simon Marvin; The internet Galaxy (2001) de Manuel Castells; Cosmopolitanism and the Geographies o freedom (2009) de David Harvey.

Rem Koolhaas, quien al mismo tiempo que teoriza, participa en la construcción de ciudades, en La ciudad genérica (1997) un escrito muy provocador, apunta una uniformización en los nuevos es- 
pacios de la globalidad, cuestionando: "¿La ciudad contemporánea es como el aeropuerto contemporáneo ¿todos iguales?" "¿Es posible teorizar esta convergencia? ¿Y si es así, a qué configuración final se está aspirando? ¿La convergencia sólo es posible a costa de despojarse de la identidad?" (p. 6). ${ }^{3}$

Abundando en su argumento señala: " $Y$ si esta homogeneización aparentemente accidental -y usualmente lamentada- fuese un proceso intencional, ¿un movimiento consciente alejándose de la diferencia hacia la semejanza?", para finalmente apuntar: "¿Qué queda después de que se ha despojado de la identidad?": ¿Lo genérico? (Koolhaas, 1997, p. 6). Entonces en su discurso resalta una fuerte irrupción de globalización en la economía, la cultura, las formas de urbanización, las expresiones y contenidos de la arquitectura y, en la cuestión de la identidad. Aunque si bien habla de ciudades iguales, ciudades genéricas que se despojan de su identidad; siguiendo la lógica de su discurso, es un hecho que las ciudades están evolucionando hacia otras pertenencias, adquiriendo otras identidades.

Dolorosamente las imágenes de la nueva época que embellecen, se complementan con otras, las que con el ascenso del neoliberalismo ha obligado a otros aspectos de la postmodernidad, al generarse zonas donde la posesión de servicios básicos en ocasiones no llega a nivel de básico, a la vez que las condiciones de las viviendas son lamentables, tal como ocurre en ranchos, pueblos jóvenes, ciudades perdidas o callampas. Aquí es patente la acción limitada del Estado, y la irrupción de empresas privadas en el control de servicios como agua, electricidad o basura, pese a experiencias que señalan fallas entre la lógica o racionalidad con la que trabaja el Estado y con lo que lo hace la empresa privada.

$Y$ en efecto, los datos y la realidad dan cuenta de aquellas contradicciones, de acuerdo con la Comisión Económica para América Latina y el Caribe (CEPAL), "En 2014, el 10\% más rico de la población de América Latina había amasado el 71\% de la riqueza de la región" (Alicia Barcena y Byanyima Winnie 2016, loc. cit.). De ahí las muestras de preocupación expresadas en reuniones, acuerdos y estudios respecto al despliegue de la nueva economía y del quehacer empresarial por parte de los organismos que intentan regular la economía a nivel mundial, como la propia Organización de Naciones Unidas, el Banco Mundial o la Organización para la Cooperación y el Desarrollo Económico, con el objetivo de encausar la nueva dinámica económica. Respecto de esa situación que afecta a la población en condiciones de pobreza en las ciudades, loannis $N$. Kessides (2004) señala:

La mayoría de las evaluaciones que conciernen a la reorganización y la privatización del sector infraestructura se han enfocado en el análisis del rendimiento operativo y económico: productividad laboral, calidad del servicio, inversión y expansión de redes, así como rendimiento y valoración del mercado. Sin embargo, una eficiencia y rendimiento mayores podría ser desventajoso para los trabajadores, los clientes y para otros grupos, como resultado del aumento de precios y del empobrecimiento tanto de niveles y condiciones de empleo como de los servicios (p. 264).

\section{La Ciudad de México y el posturbanismo contra- dictorio}

La nueva dinámica económica mundial requiere la concentración de mejores condiciones para producir, y en el caso de las ciudades mexicanas la elaboración y ejecución de planes o programas ur-

\footnotetext{
${ }^{3}$ Esta argumentación, recuerda las proclamas de Le Corbusier en Urbanismo (1924) al negar tradición e historia y llamar a un nuevo urbanismo y, a Roberto Venturi en Complexity and contradiction in architecture (1966) por su perspectiva de buscar romper con lo actual y simple, para abogar por la complejización.
} 
banos y regionales, ha intentado proyectarse en ese sentido; lastimeramente estos se han convertido en meros instrumentos institucionales e ideológicos al no lograr conjuntar los intereses de los principales gestores de las dinámicas territoriales: los grupos empresariales de todo tipo. En esa vía y por lo manifiesto en algunas ciudades como Monterrey, Guadalajara, Aguascalientes, Puebla o la Ciudad de México, puede decirse que, pese a la solidez mostrada por los instrumentos de planeación, en tanto se estructuran y fundamentan con la seriedad debida, éstos se hacen endebles y limitados ante los diversos intereses de las comunidades a las que intentan atender, aunado a los límites jurídicos y administrativos en que se desenvuelven, de ahí el urbanismo desigual y fragmentado que ha venido resultando.

Desde inicios de los ochenta del siglo pasado con el marco de una crisis que venía de los setenta, el Estado dio paso a una serie de reformas que permitieron a las empresas hacerse de sectores que estaban en sus manos o por el reguladas, como fue el caso de la reforma al artículo 27 de la Constitución, que permitió colocar a la venta de tierras e impulsar un nuevo proceso inmobiliario; aunado a la inclusión del país primero al Acuerdo General sobre Aranceles Aduaneros y Comercio (GAT) en 1986, y luego al Tratado de Libre Comercio (TLC) en 1994, todo en un ambiente donde la sociedad mexicana elevó sus exigencias respecto a satisfactores (Tello, 2011). En este marco, se produjeron multitud de proyectos en la industria, turismo, comercio, finanzas, vivienda, infraestructura, equipamiento, etcétera, con lo que el país ha tratado de adaptarse a las nuevas regiones económicas y paliar la crisis.

En esos procesos de renovación económica, social, cultural y territorial donde es notoria una profundización de las desigualdades, sigue cobrando una singular importancia la participación del Estado aun con el fuerte tono empresarial -y pese a los intentos por minimizar efectos por las políticas con mayor contenido social del actual presidente Andrés Manuel López Obrador (1918-1924)-; por lo que en el desenvolvimiento de la economía, sigue existiendo una amplia injerencia de los grupos más poderosos del país, muchos de ellos con vínculos económicos en el exterior (Tello, 2011), lo cual se observa en el carácter de muchas de los políticas aplicadas a las ciudades.

Así, la Ciudad de México arribó al siglo XXI con transformaciones en todos los ámbitos. De acuerdo con el Instituto Nacional de Estadística, Geografía e Informática en la Zona Metropolitana del Valle de México (ZMVM) -conformada por partes del Estado de México, la ahora Ciudad de México y el Estado de Hidalgo, y en conjunto también llamada Ciudad de México (Ver Figura 6) - se concentraban en 1910, 20,116,842 de habitantes (INEGI, 2014) aproximadamente el 17 por ciento de la población del país, se generaba el 27 \% PIB del país de acuerdo con el Programa de Ordenación de la Zona Metropolitana del Valle de México (POZMVM) (Fondo, 2011). Estas cifras permiten entender las formas de concentración y expansión de la ya megalópolis, las exigencias de renovación de sus espacios, y algunas de las características de las condiciones en que se desenvuelve la población.

Si se considera que de acuerdo con estimaciones el Consejo Nacional de Evaluación de la Política de Desarrollo Social (Coneval), de una población en condición de pobreza del país, cifrada en 53'349,900 habitantes en 2015, 8'054,703 se situaban en el Estado de México, 2'457,084 en el Distrito Federal y 1'426,640 en el Estado de Hidalgo, entidades que albergan a la ZMVM. Así mismo, que los municipios o demarcaciones con el mayor número de personas en situación de pobreza en 2015 fueron: Ecatepec de Morelos $(786,843)$, Iztapalapa (665,408); Chimalhuacán (483,845), Nezahualcóyotl $(393,721)$; Gustavo A. Madero $(344,966)$, Naucalpan de Juárez (2018b); mientras que los espacios con el menor número de pobres son las ahora alcaldías de Benito Juárez y Miguel Hidalgo (Coneval, 2018a). 
Figura 6. La Zona Metropolitana del Valle de México y área de influencia

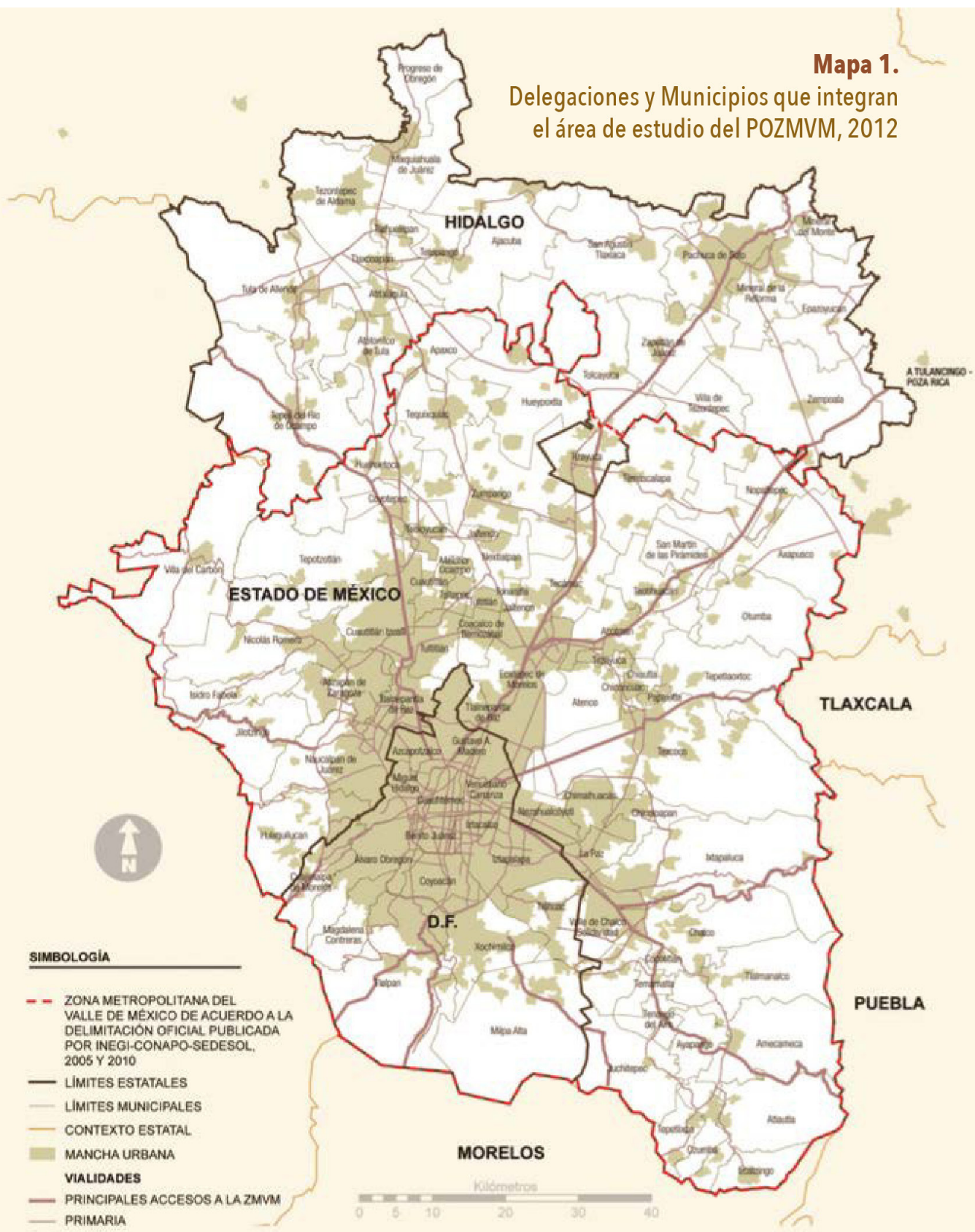

Fuente: Fondo, (2011). 
Todos esos datos en su lado cualitativo, dibujan una determinada ocupación del territorio, una multitud de relaciones en el interior y con el exterior de la ciudad, y una expresa demanda y entrada de satisfactores. Lo anterior significa: el ingreso de grandes volúmenes de alimentos 0 agua potable $y$, en consecuencia, una alta generación de residuos sólidos y líquidos. Agréguese, además, la permanente edificación o creación de nuevos espacios, los cuales ineludiblemente si no se erigen en espacios reciclados, se realizan sobre otrora zonas de cultivo 0 reservas naturales.

Con todos los problemas que implica dirigir el crecimiento de una urbe con la magnitud de la Ciudad de México, las autoridades con sus posibilidades y límites han logrado que esta funcione y puedan desarrollarse las actividades que la caracterizan. $Y$ en efecto entre los esfuerzos que lo gobiernos han despegado en esta nueva época destacan: el Plan Director para el Desarrollo Urbano del Distrito Federal (1976), el Programa de Ordenación de la Zona Metropolitana del Valle de México (POZMVM) en sus versiones 1998 y 2012, de los cuales cabe abundar, estos se incluyen dentro de un sistema nacional de planeación, que se conduce entre tumbos.

El Plan Director para el Desarrollo Urbano del Distrito Federal, un añejo proyecto planteado desde 1927 por el arquitecto Carlos Contreras para la Ciudad de México y su región, en su parte medular consideró la conformación de una red vial integrada "por dos anillos concéntricos de acceso controlado, ligados por vías radiales y por numerosos ejes N-S y E-W en forma cuadrícula irregular"; que en la pretensión de activar a la ciudad y relocalizar industrias en la periferia, racionalizar recorridos y generar nuevos corredores urbanos, fue determinante para la inserción de comercios y servicios de todo tipo, aunado a la proliferación de plazas comerciales, que se asentaron en los corredores resultado de la aplicación del Plan. Luego entonces este Plan, renacionalizó a la ciudad al generar amplios espacios para las actividades de una posmodernidad que se desarrollaría después de la mano del neoliberalismo.
El instrumento de planeación más reciente es el POZMVM de 2012 -el cual es una actualización del de 1998- donde dando un diagnóstico pormenorizado de los problemas y por supuesto de posibilidades de remontarlos, y se afirmaba:

Se reconoce un patrón general de desigualdades multidimensionales (ingreso, dotación de infraestructura, equipamiento, servicios, accesibilidad y fuentes de empleo) que pone en contraste un espacio privilegiado con punto de gravedad en el centro, la zona poniente del D.F. y los municipios contiguos del Estado de México, que se expande en forma de una espina dorsal del sur al norponiente y se va degradando hacia las periferias [...]. Las actividades comerciales y de servicios del sector moderno muestran un patrón concéntrico en 5 delegaciones del D.F. y dos municipios mexiquenses al noroeste del D.F., que se asocia con la espina dorsal de la población de altos ingresos, que recorre el territorio del surponiente hacia el centro y el norponiente. En el espacio restante se dispersan las actividades del sector tradicional en zonas habitacionales y de usos mixtos ubicadas en el D.F., principalmente en los viejos corredores industriales tradicionales, y en los municipios conurbados (Fondo, 2011, p. 272).

Con base en ello, el documento planteó líneas de acción con la idea de lograr una metrópoli equitativa para sus habitantes, donde son aspectos importantes: la inclusión, la redistribución y la seguridad, los cuales se han intentado atender, a partir de: afianzar condiciones de sustentabilidad conservando y atendiendo las cuestiones del agua, aire y residuos sólidos; reactivar la economía -donde las intervenciones urbanas son fundamentales-; innovar, promocionar y simplificar la administración; estimular la responsabilidad ambiental y social; $y$, actuar y apuntalar la cuestión de la gobernabilidad, intentando la integración al respecto de las tres entidades que conforman a la ZMVM (Fondo, 2011). 
Desafortunadamente y pese la existencia de propuestas serias como las reseñadas, las relaciones entre las demarcaciones que componen la mancha urbana esto es: la ahora Ciudad de México, y los municipios conurbados del Estado de México e Hidalgo, no han permitido regular o controlar un desarrollo conjunto dando al traste con las pretensiones de esos ejercicios de planeación; desde esa perspectiva, cobran vigencia los añejos llamados a tratar a las conurbaciones como una unidad administrativa. Y en efecto desde los años treinta en el Plan Regulador de 1933 Carlos Contreras hizo un llamado al respecto, de igual modo, en los años cuarenta el arquitecto Enrique Guerrero Larrañaga (1945), argumentó respecto "a la necesidad de controlar la conurbación con los municipios aledaños a la urbe" (p. 19), en razón a que como sostenía, sobrevivían caciquismos, posturas políticas y desacuerdos de las diferentes entidades, y, por tanto, se profundizaban problemas en el área.
Así, con los señalados límites, los esfuerzos de autoridades y de las propuestas de profesionales del urbanismo, la dinámica de la Zona Metropolitana del Valle de México ha discurrido entre diversos procesos y con particulares dinámica; en ese sentido, vale la pena rescatar o subrayar, situaciones plausibles generadas por ejercicios del urbanismo en la nueva época de la ciudad, abierta en los años sesenta del siglo XX y en lo que va de este siglo XXI.

Uno: Al peatonizar calles como Madero y Regina (Ver Figura 7), la consolidación de las imágenes de avenidas importantes como Reforma (Ver Figura 8), y la renovación del Centro Histórico. Donde en el caso de este último, se han remodelado fachadas con valor patrimonial, se cambiaron añejas tuberías de drenaje y agua potable, se introdujo una red de fibra óptica para mejorar tecnologías de la información y de vigilancia, se trasladaron vendedores ambulantes al oriente de este centro, etcétera. En ese mismo sentido, se han revitalizado pueblos originarios absorbidos por la ciudad, como son los casos de Xochimilco, Coyoacán o Iztacalco donde se ha cuidado la imagen. ${ }^{4}$

\footnotetext{
${ }^{4}$ Nan Ellin en Postmodern Urbanism (1996) señala: "La principal característica del urbanismo postmoderno es el contextualismo (histórico, físico, social y cultural) en contraste con el rompimiento del urbanismo moderno con el pasado y el sitio" (Ellin, 1996, p. 163).
} 
Figura 7. Conversión de la calle de Regina a peatonal

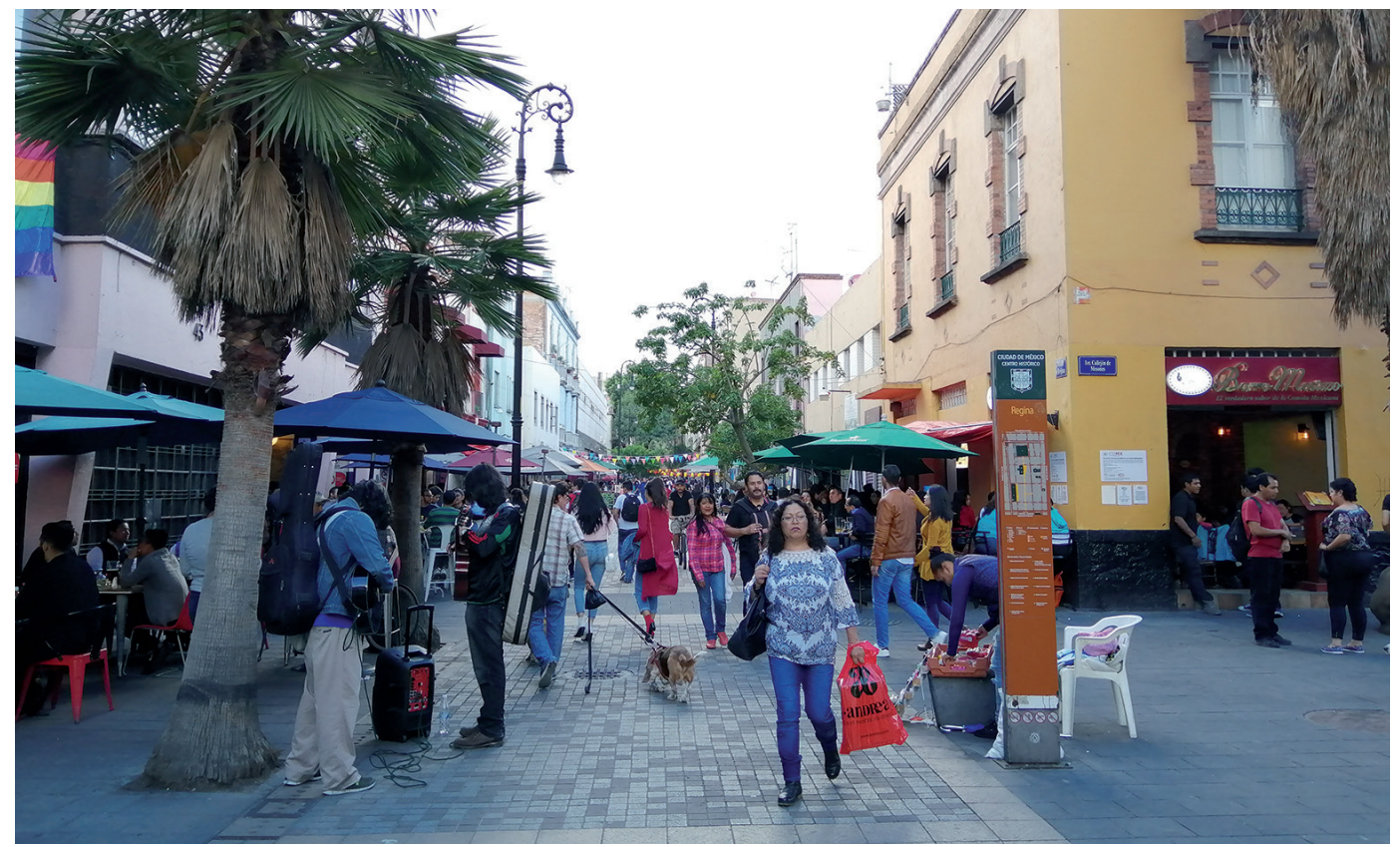

Fuente: Sánchez, (2019).

Figura 8. Avenida Reforma, el aparador de México

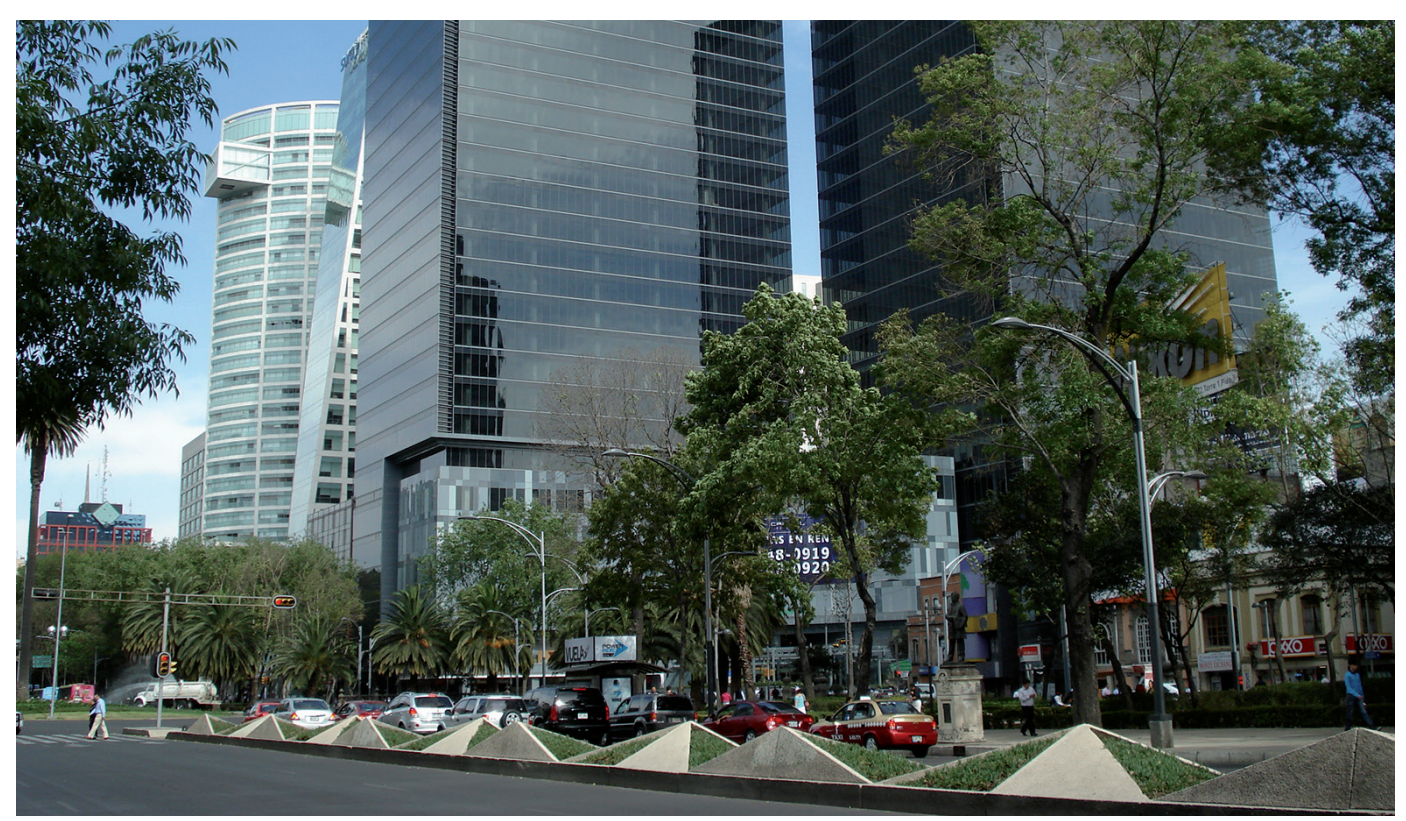

Fuente: Sánchez, (2016). 
Dos: El establecimiento de espacios corporativos donde se funden servicios, comercios y viviendas, como es el caso del complejo de Santa Fe -a lado de asentamientos irregulares- (Ver Figura 9), aunado a la proliferación de grandes y pequeñas plazas comerciales, donde en ambientes por demás controlados, se ha permitido o reconfirmado la estancia de tiendas departamentales, restaurantes de cadena, tiendas de comida rápida, bancos, etcétera; y por supuesto: nuevas cotidianidades.

Figura 9. El corporativo Santa Fe y sus periferias

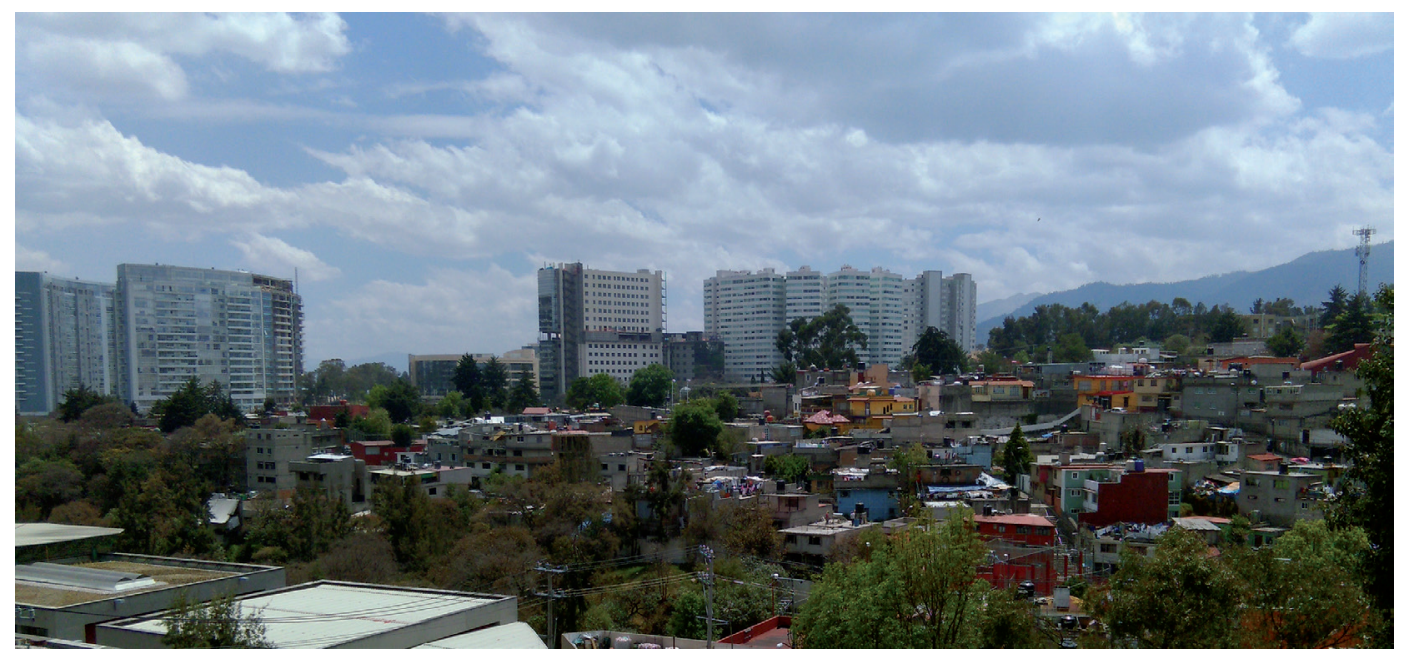

Fuente: Sánchez, (2016).

Tres: La reutilización de otrora zonas industriales o comerciales, como la antigua planta de la Ford al poniente de la ciudad, ahora con un complejo cultural denominado Plaza Carso donde sobresale el Museo Soumaya (2011); o la vieja zona industrial de Ferrería al noroeste de la urbe, que se reinventó como la "ciudad del conocimiento", y que alberga una universidad pública desde los años setenta, y en el presente-pese a la resistencia de habitantes de la zona-, una universidad privada, una plaza de oficinas, servicios y comercios denominada Tecnoparque, y la Arena Ciudad de México (2012).

Cuatro: Para comunicar los nuevos desarrollos dándole mayor movilidad a la ciudad: La renovación de vialidades y modos de transporte iniciados con los Ejes viales (1978), el sembrando distribuidores viales y segundos pisos (2005) y libramientos, además de introducir sistemas de trans- porte colectivo como el Metro (1969), el Metrobús (2005) y el Tren Suburbano (2008) que conecta a la ciudad con el norte, el Mexibus (2010) y, el tren que conectará a Toluca con la Ciudad de México aún en construcción.

Cinco: Una situación que poco se nota del urbanismo: la atención a los sistemas de abastecimiento de agua y su desagüe, que en el primer caso siguen siendo fundamentales el sistema Lerma, el Cutzamala, y fuentes subterráneas, para atender la demanda de millones de habitantes. Mientras que, en cuestión de desagüe, se atendieron los problemas de zonas inundables de Ecatepec e Iztapalapa, ya que al construirse el Túnel Emisor Oriente se ha incrementado la capacidad del Sistema de Drenaje Profundo (1967-75) ofreciendo mayor seguridad en el rubro. 
Seis: Políticas ambientales y de salud ${ }^{5}$ pretendiendo mejorar la calidad del aire, induciendo el uso de espacios abiertos y verdes, la mejora de gasolinas y procesos de combustión de automotores, a la vez de motivar el uso de la bicicleta utilizando grandes avenidas como Reforma los fines de semana; a lo cual se agrega la delimitación de vías para los ciclistas.

Siete: El rescate de parques y camellones, instalando aparatos para hacer ejercicios, y juegos para niños, acción que ha tenido el objetivo de generar espacios de convivencia e identidad para actuar a la vez en cuestiones de inseguridad. Lo anterior se ligó al uso de las partes bajas de puentes viales al instalar pequeños locales de servicios, lo cual ha contribuido a disminuir objetivamente la inseguridad.
Ocho: Sin la participación del Estado: el impulso a un urbanismo defensivo (Méndez, 2010) (Ver Figura 10) que se expresa en la creación de conjuntos residenciales que prometen un estatus deseado y un espacio seguro, y que se extienden como espacios cerrados o encerrados al interior de la ciudad, generando otras formas de habitar y de relación. De ahí fraccionamientos exclusivos con casas 0 departamentos con áreas de más de 300 metros cuadrados, en lugares como Lomas Country Club, Interlomas o Lomas Bezares al poniente de la ciudad 0 en su caso, conjuntos más modestos en zonas de clase media.

\footnotetext{
${ }^{5}$ En abril de 2020, al atender las observaciones realizadas por los dictaminadores las cuales agradezco, no fue posible hacer de lado la irrupción del Coronavirus COVID-19 en una condición global y los efectos que en presente causa en la Ciudad de México. Apareció primero en zonas de buen poder económico, pero dadas las múltiples actividades y el nivel de movilidad de sus millones de habitantes, se ha desplazado a otras partes; y como las grandes epidemias que afectaron al mundo en el siglo XIX y principios del XX, seguramente los más afectados serán los grupos con menores posibilidades económicas. Si por las presumibles muertes, pero también porque el necesario aislamiento establecido, afecta a quienes no tienen ingresos suficientes y habitan lugares con no muy buenas condiciones; en ese sentido, habrá que reflexionar respecto a que el urbanismo sigue teniendo tareas al moldear espacios, y por tanto, atender las situaciones que por su carácter le incumben.
} 
Figura 10. Urbanismo defensivo en Atizapán o fraccionamiento cerrado

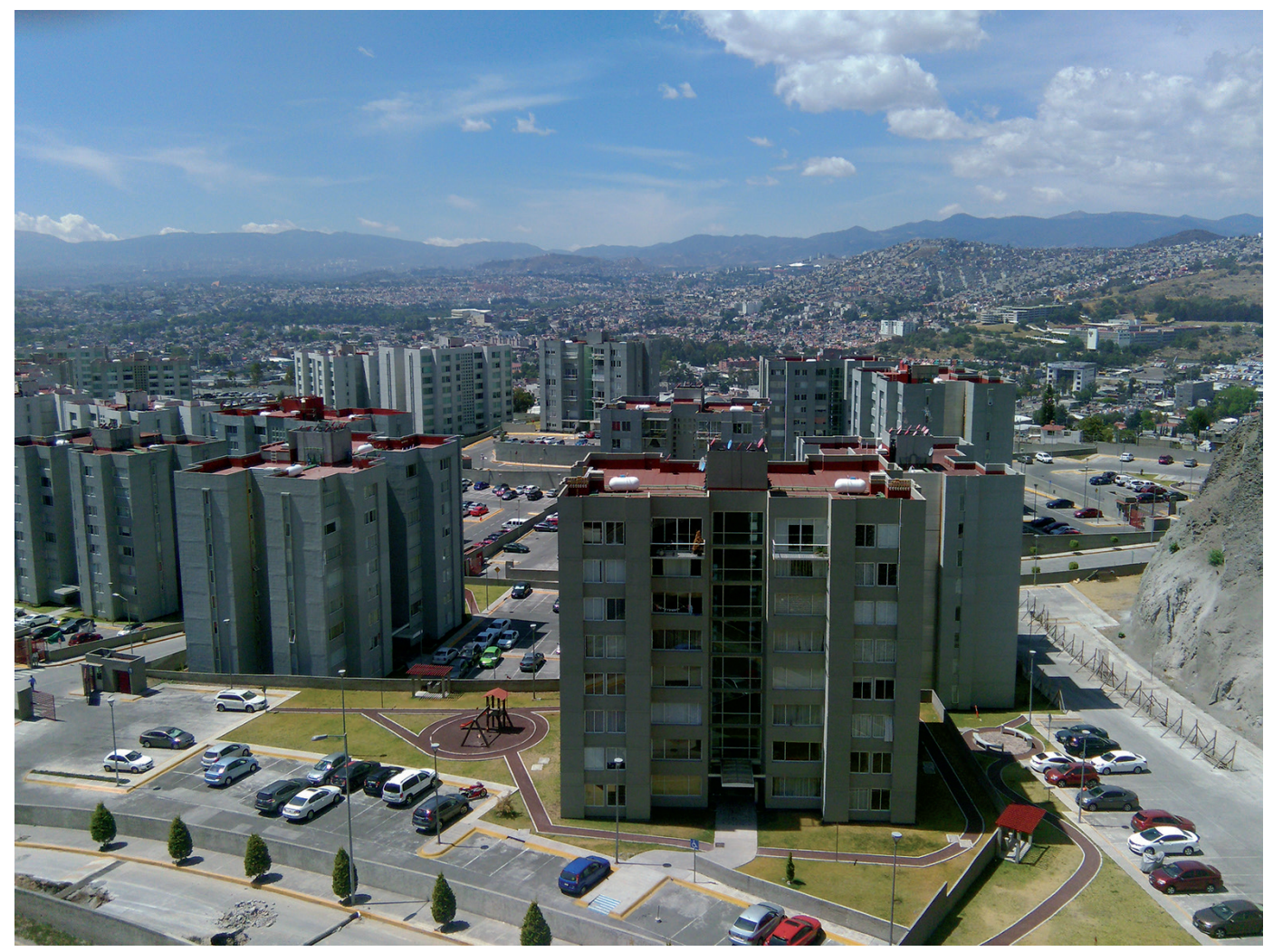

Fuente: Sánchez, (2016).

Nueve: La existencia de un urbanismo de autogestión en la periferia de la ciudad, realizado sobre todo por pequeños fraccionadores y gente de escasos recursos, que enfrentan el lado lamentable de la postmodernidad, y del cual han resultado es- pacios que no se disfrutan pero sí se padecen; destacando los surgidos en Iztapalapa, Chimalhuacán, Tlalnepantla, Ecatepec, Valle de Chalco, Tizayuca 0 Naucalpan (Ver Figura 11). 
Figura 11. Asentamientos irregulares en Naucalpan, un municipio conurbado

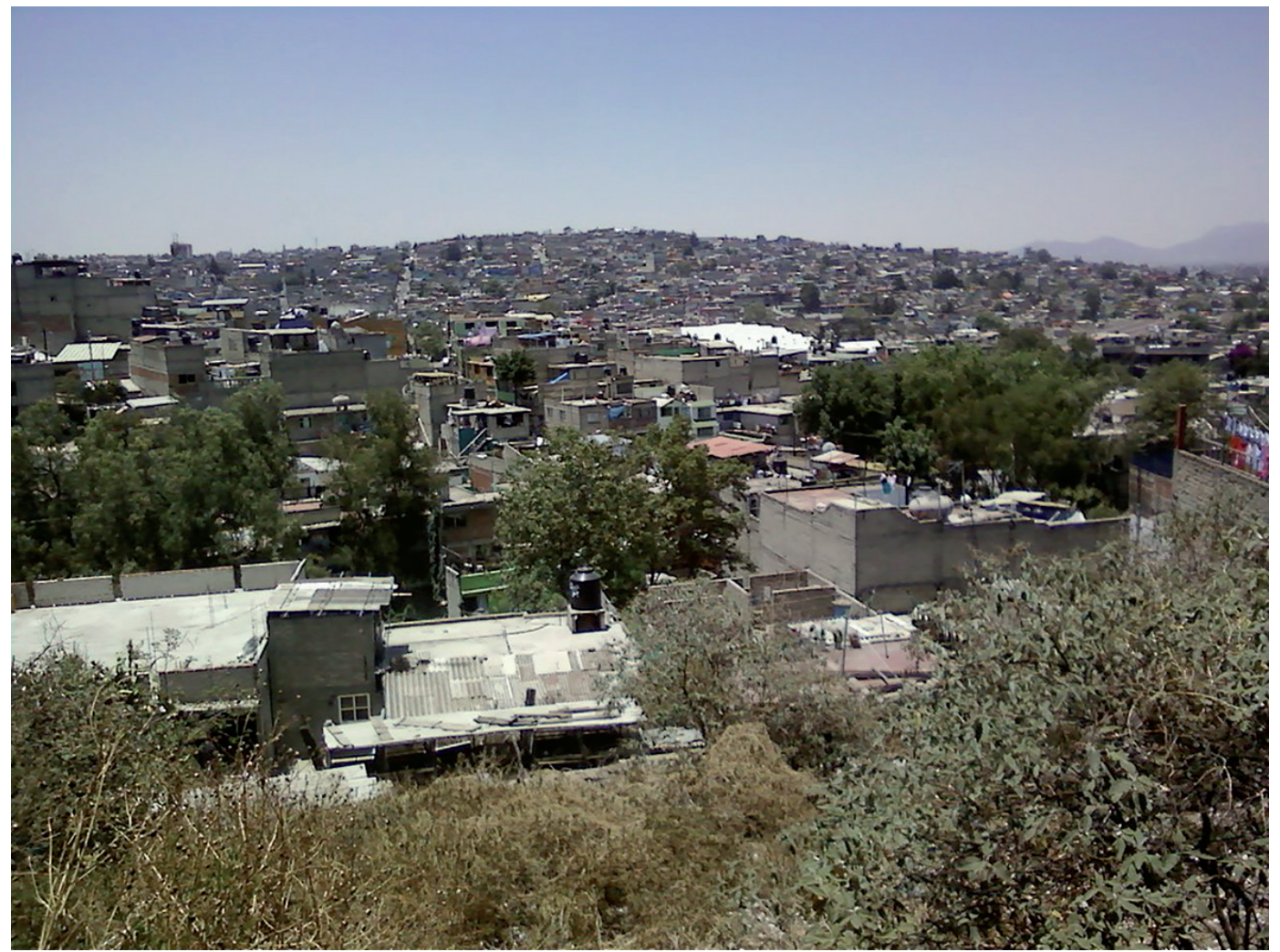

Fuente: Sánchez, (2016).

Diez: Como expresiones de ese mundo neoliberal, global y postmoderno: la erección de edificaciones con espacios por demás estudiados y con formas rebuscadas que semejan a las de cualquier gran ciudad del mundo; mientras en la otra parte, proliferan las proyectadas con la guía única de la necesidad, autoconstruidas, con estructuras endebles, en algunos casos con materiales de desecho, sin los servicios más elementales, y muchas de las veces irregulares en su forma de propiedad.
Once: Como acciones político-administrativas que han condicionado la mejora de espacios: Intentos por perfeccionar la gobernanza del conjunto de la gran Ciudad de México -aun con una reducida y preocupante participación ciudadana-, pero sin intentar, un necesario gobierno metropolitano para así controlar a las tres unidades administrativas que la albergan y de ese modo, hacer más factible su planeación. Por supuesto en esta condición, si bien es fundamental la actitud de los gobiernos, también lo es de los gobernados. 


\section{Conclusiones}

Neoliberalismo, globalidad y postmodernidad son los determinantes de la nueva dinámica de la ciudad de México, donde la realidad muestra altos grados de desigualdad y exclusión. Lo anterior si en términos generales se compara el sur y poniente donde se localizan las mejores condiciones, con el norte y oriente donde subsisten las peores. Partes donde en las primeras imperan sectores medios y altos, los cuales se han beneficiado con los destellos de desarrollo del país; mientras en las segundas, se han objetivado políticas económicas erróneas que han obligado a migraciones del campo a la ciudad, invasiones de terrenos, y procesos de autoconstrucción y autoplaneación.

De ahí que se siga insistiendo en buscar un desarrollo económico más equilibrado y acciones urbanas más incluyentes, en ese mismo sentido, entender que políticas urbanas bien estructuradas, pueden tener buenos resultados para la economía y cumplir con aspiraciones de ganancias de empresarios y mejores niveles de vida en todos los sectores sociales; y que, una política económica sin un sustento territorial firme producto de un buen ejercicio del urbanismo, no tiene futuro, y no podrá actuar a favor de mejoras. En ese sentido es que sigue siendo imprescindible la intervención del Estado en estos asuntos, si bien no con la profundidad de antaño, tiene y debe conservar su poder de regulador y de decisión, para así orientar acciones sobre espacios y sectores más amplios, sin dejar de mantener rentabilidades al hacerlas más fluidas y estables.

De igual modo, en el ámbito político y profesional, tiene que reconocerse la importancia de hacer urbanismo, y partir de sus posibilidades para atender muchos de los problemas que hoy aquejan. El descontinuado Marx de observar muchos escritos sobre cuestiones urbanas diría: Los estudiosos de lo urbano se han dedicado a interpretar de diversas maneras a la ciudad, pero de lo que se trata es de transfórmala. Por lo que entender que el urbanismo debe ser entendido como un instrumento teórico, técnico, político, jurídico, administrativo y particularmente práctico, por lo que debe conjuntar: 1. Posturas teóricas que interpreten problemas y propongan soluciones, en tanto lo que en el momento domina es la crítica; 2 . Capacidad técnica para elaborar e implementar propuestas lo cual requiere profesionales bien preparados en la disciplina; 3 . Unidades territoriales únicas en lo jurídico y administrativo para evitar conflictos de poder e imposibilidades para actuar; 4. Órganos de planeación independientes que sobrepasen periodos de gobierno para hacer planeación a corto, mediano y largo plazo; 5 . Una administración que conduzca sólidamente propuestas y acciones para lograr mejores resultados; 6 . Control del suelo para evitar especulación al gestarse planes urbanos; 7. Una sólida participación de las comunidades en el proceso para dar viabilidad a los ejercicios; 8 . Solvencia financiera para realizar el conjunto de acciones; y 9 . Decisiones políticas firmes, para que lo pretendido tenga mayor éxito.

Es claro que se requiere una reorientación de políticas económicas y del urbanismo en el conjunto del país, y por supuesto en su capital, pues las carencias siguen obligando a la gente más afectada por las políticas económicas a emigrar hacia esta última, a ciudades más pequeñas, hacia Estados Unidos, o como ocurre actualmente, a sumarse a las actividades delictivas que hoy preocupan. Se tienen que seguir ensayando políticas adecuadas para la ciudad, considerando que muchos de sus problemas tienen solución mejorando otros territorios del país y desde perspectivas sociales integrales, ya que innegablemente problemas como las migraciones o el crecimiento de actividades delictivas tienen como origen la insatisfacción de las necesidades básicas, debido a la falta de empleos, de escuelas, de oportunidades, o por habitar asentamientos deprimente. Habrá que plantear que las acciones estatales e inducidas por los grupos empresariales, no pueden tener un buen futuro si no se considera el bienestar del conjunto de la sociedad. 


\section{Referencias}

Amábilis, M. (1933). Donde. Imp. E. Gómez.

Bárcena, A.; Byanyima, W. (2016) "América Latina y el Caribe es la región más desigual del mundo. ¿Cómo solucionarlo? www.cepal.org/es/articulos/2016-america-latina-caribe-es-la-region-mas-desigual-mundo-como-solucionarlo.

Consejo Nacional de Evaluación de la Política de Desarrollo Social (2018a). Medición de la pobreza, Estados Unidos Mexicanos, 2016. www.coneval.org.mx.

Consejo Nacional de Evaluación de la Política de Desarrollo Social (2018b). Pobreza a nivel municipal 2015. www.coneval.org.mx.

Departamento del Distrito Federal. (1976). Plan Director para el Desarrollo Urbano del Distrito Federal. México. www.dof.gob.mx/nota_detalle.php.

Espeche, C. (2003). Los nuevos sujetos de la protesta social y sus reivindicaciones. Las demandas de participación popular frente al desafío de una profundización de la democracia en América Latina. Informe final del concurso: Movimientos sociales y nuevos conflictos en América Latina y el Caribe. Programa Regional de Becas CLACSO. http://bibliotecavirtual. clacso.org.ar/ar/libros/becas/2002/mov/espeche.pdf.

Guerrero L., E. (1945/2004). "Urbanismo Oficial" en Arquitectura y lo demás, No.1. En Ríos Garza Carlos (Comp.). (2004). Arquitectura y lo demás, 1945-1950. Raíces Digital No. 2. V.1. (pp. 16-21). UNAM.

Habermas, J. (1981/1999). Teoría de la acción comunicativa. T. II. Taurus.

Instituto Nacional de Estadística, Geografía e Informática. (2009). "Participación económica de los municipios más importantes en México: visión censal" Censos Económicos 2009. www. inegi.org.mx/est/contenidos/espanol/proyectos/censos/ce2009/pdf/M_Municipios_ mas_importantes_Mexico.pdf

Instituto Nacional de Estadística, Geografía e Informática. (2014). Cuaderno estadístico y geográfico de la zona metropolitana del Valle de México 2014. www.inegi.org.mx/contenidos/productos/prod_serv/contenidos/espanol/bvinegi/productos/nueva_estruc/valle_ mex/702825068318.pdf.

Jameson, F. (1991/1998). Teoría de la postmodernidad. Trotta.

Jameson, F. (1994/2000). Las Semillas del Tiempo. Trotta.

Kessides, I. (2004). Reforming infrastructure. World Bank/Oxford University Press.

Koolhaas, R. (1997/2006). La ciudad genérica. Gustavo Gili.

Lefebvre, H. (1962/1995). Introduction to Modernity. Verso.

Lyotard, J. (1979/1991). La condición Postmoderna. Cátedra,

Méndez, E., et al. (2010). Arquitecturas alegóricas y urbanismos defensivos. Colegio de Sonoral Universidad de Sonora.

Mills, C. (1959/1969). La imaginación sociológica. Instituto del Libro Edición Revolucionaria.

Mittelman, J. H. (2000). The Globalizatión Syndrome. Princenton University Press.

Organización para la Cooperación y el Desarrollo Económicos. (1915). Estudios Territoriales de la OCDE. Valle de México. OCDE. https://www.gob.mx/cms/uploads/attachment/file/56213/ valle-de-mexico-OCDE.pdf

Paz, 0. (1986/1995). "Poesía y modernidad" en Obras Completas T.1. Fondo de Cultura Económica. 
Puello-Socarrás, J. (2015). Neoliberalismo, antineoliberalismo, nuevo neoliberalismo. episodios y trayectorias económico-políticas suramericanas (1973-2015) en Rojas Villagra, L. (Coord.). Neoliberalismo en américa latina. crisis, tendencias y alternativas. Asunción: Consejo Latinoamericano de Ciencias Sociales. http://biblioteca.clacso.edu.ar/clacso/ gt/20151203044203/Neoliberalismo.pdf.

Rossi, A. (1966/1992). La arquitectura de la ciudad. Gustavo Gili.

Smith, M. P. (2001). Transnational urbanism. Blackwell.

Tello, C. (2011). Estado y desarrollo económico. Universidad Nacional Autónoma de México.

Touraine, A. (1992/2000). Crítica de la modernidad. Fondo de Cultura Económica.

\section{Figuras}

Figura 1. Sánchez, G. (2014). El influyente corporativo: La Defensa en París. Archivo del autor.

Figura 2. Sánchez, G. (2015). Potsdamer Platz en Berlín, redirigiendo la postmodernidad. Archivo del autor.

Figura 3. Sánchez, G. (2018). Moscú con parte de su postmodernidad: Moscú City. Archivo del autor.

Figura 4. Sánchez, G. (2014). La zona de Las Condes en Santiago de Chile. Archivo del autor.

Figura 5. Sánchez, G. (1995). Biblioteca pública en San Antonio Texas. Archivo del autor.

Figura 6. Fondo Metropolitano del Valle de México-Programa Universitario de Estudios Sobre la Ciudad. (2011). La Zona Metropolitana del Valle de México y área de influencia. Programa de Ordenación de la Zona Metropolitana del Valle de México. México. www.economia. unam.mx/cedrus/descargas/POZMVM.

Figura 7. Sánchez, G. (2019). Conversión de la calle de Regina a peatonal. Archivo del autor.

Figura 8. Sánchez, G. (2016). Avenida Reforma, el aparador de México. Archivo del autor.

Figura 9. Sánchez, G. (2016). El corporativo Santa Fe y sus periferias. Archivo del autor.

Figura 10. Sánchez, G. (2016). Urbanismo defensivo en Atizapán o fraccionamiento cerrado. Archivo del autor.

Figura 11. Sánchez, G. (2016). Asentamientos irregulares en Naucalpan, un municipio conurbado. Archivo del autor. 